\title{
Gap Confinement Effect of Tandem Nanochannel System and Its Application in Salinity Gradient Power Generation
}

\author{
Yuting Wang $^{a}$, Huaxiang Chen ${ }^{b}$, and Jin Zhai ${ }^{a *}$
}

Dr. Y. Wang, Dr. H. Chen, Prof. J. Zhai,

${ }^{a}$ Key Laboratory of Smart bioinspired Interfacial Science and Technology of Ministry of Education School of Chemistry Beijing Advanced Innovation Center for Biomedical Engineering

\author{
Beihang University \\ Beijing 100191, P. R. China \\ E-mail: zhaijin@buaa.edu.cn \\ b Petrochemical Research Institute, China National Petroleum Corporation \\ Energy east road, Shahe Town, Changping District, Beijing 102200, P.R.China
}




\section{Content of Supporting Information}

1. The properties of the cylindrical PET porous membranes.

Figure S1: Geometrical parameters of the cylindrical PET porous membranes.

Table S1: The tested Zeta potential of the cylindrical PET porous membranes.

Equation S1: The estimated surface charge density of 1D PET nanochannels.

2. The properties of channel $1 \& 2$ bi-channel system. (Corresponding to chapter 2.1 of the manuscript)

Figure S2: I-V curves of cylindrical channel unit in different $\mathrm{pH}$.

Figure S3: Resistance of channel 1, channel 2 and channel 1\&2 system.

Figure S4: Equivalent circuit diagram of channel 1\&2 system.

3. The supplymentary ionic transport behavior of channel $1 \& 3$ system in constant concentration solution. (Corresponding to chapter 2.2 of the manuscript)

Figure S5: Caculation model of channel 1\&3 mode in constant concentration solution $(10 \mathrm{mM} \mathrm{KCl})$.

Figure S6: The simulated ionic concentration distribution and I-V curves of channel $1 \& 3$ restricted mode.

Figure S7: The simulated I-V curves, rectification ratio, cations transfer numbers $\left(t_{p}\right)$ and $C_{p} / C_{\text {total }}$ with different gap width.

4. The supplymentary ionic transport behavior of channel $1 \& 2$ system in salinity gradient solution. (Corresponding to chapter 2.3 of the manuscript)

4.1 The experimental tested data of channel $1 \& 2$ mode in salinity gradient solutions.

Figure S8: The short-circuit current $\left(I_{s c}\right)$ of the channel $1 \& 2$ system.

Table S2: The measured parameters of channel $1 \& 2$ system.

4.2 Numerical simulated parameters of channel $1 \& 2$ mode in salinity gradient solution.

Figure S9: Calculation model of channel 1\&2 system.

Figure S10: The cations and anions contribution current of channel $1 \& 2$ system.

Figure S11: The axial diffusion potential distribution of channel 1\&2 system with different stacking gaps

Figure S12: The numerical simulated cations concentration ratio $\left(C_{p} / C_{\text {total }}\right)$ by PNP equations.

5. The supplemented ionic transport behavior of tandem cellulose acetate (CAM) system in artificial seawater and river water solutions. (Corresponding to chapter 2.4 of the 
manuscript)

Figure S13: Geometrical parameters of the cellulose acetate membranes (CAM).

Figure S14: The conductance-concentration curve of CAM channel system.

Figure S15: I-V curves of a serials of CAM channel numbers.

Figure S16: The CAM channel current density with serials of external resistance.

Table S3: The measured parameters of CAM channel systems in artificial sea water and river water solutions.

6. The ionic transport behavior of PET multi-channel system in artificial seawater and river water solutions. (Corresponding to chapter 2.4 of the manuscript)

Figure S17: The schematic and ionic transport behavior of tandem PET systems.

Table S4: The measured parameters of PET systems in artificial sea water and river water solutions.

7. The time dependent power generation behavior with CAM tandem system Figure S18: Current density-time curve of CAM channel system with 10 cascade numbers without electrolyte replenishing.

8. The electrical measurement Figure S19: Equivalent circuit diagram of salinity gradient power generation systems.

9. The description of PNP equations.

10. Figure S20: The optical photograph of testing devices of the restricted mode and unrestricted mode.

11. Table S5: A comparison table with the reported power density existing in literatures.

\section{References}


1. The properties of the cylindrical PET porous membranes.

Geometrical parameters of the cylindrical PET porous membranes.

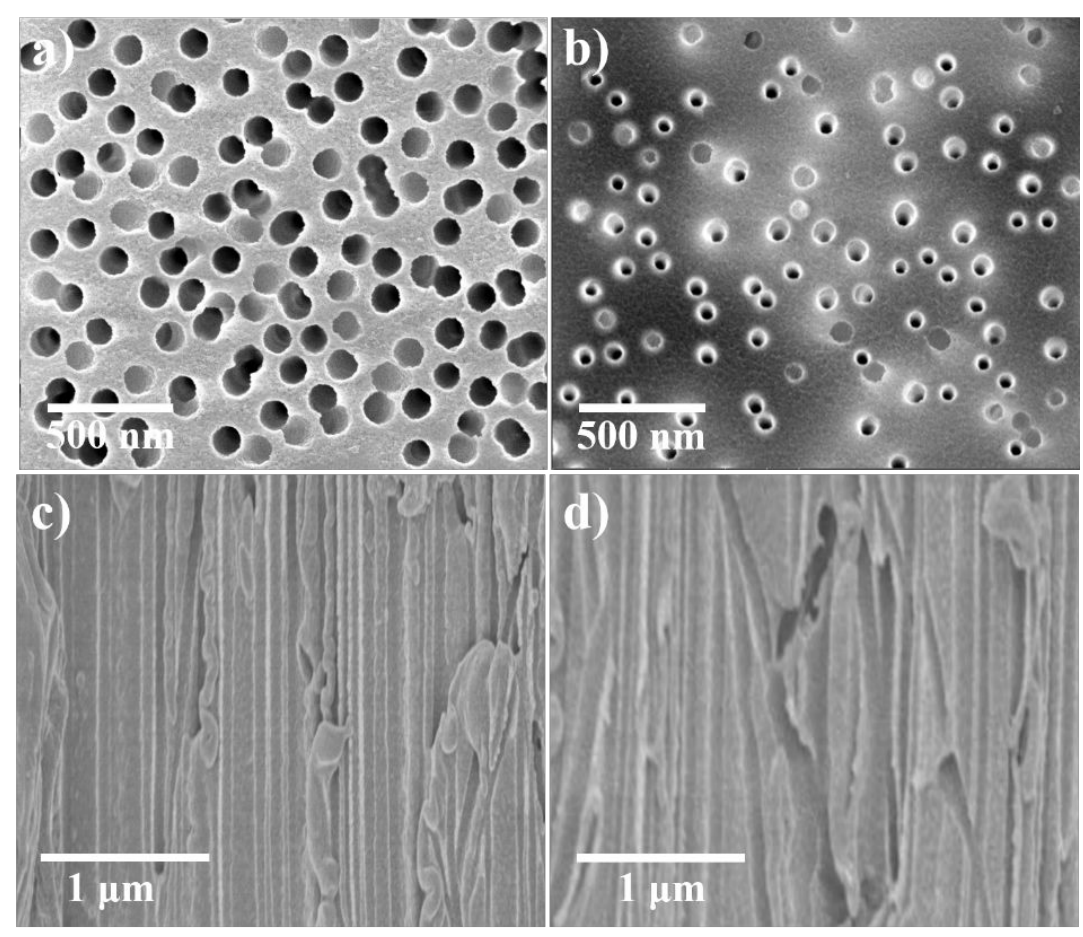

Figure S1. The SEM images of PET porous membranes. (a) channel 1 surface (pore size was $120 \pm 10 \mathrm{~nm}$ ); (b) channel 3 surface (pore size was $50 \pm 6 \mathrm{~nm}$ ); (c) channel 1 cross-section view ( $\sim 23 \mu \mathrm{m}$ in thickness); (d) channel 3 cross-section view $(\sim 23 \mu \mathrm{m}$ in thickness). 
The cationic selectivity of the cylindrical PET porous membranes

Table S1. The Zeta potential of PET membranes at different $\mathrm{pH}$ value.

\begin{tabular}{cccc}
\hline $\mathrm{pH}$ value & 3 & 7 & 11 \\
\hline Zeta potential $(\mathrm{mV})$ & 14.26 & -41.15 & -50.81 \\
\hline
\end{tabular}

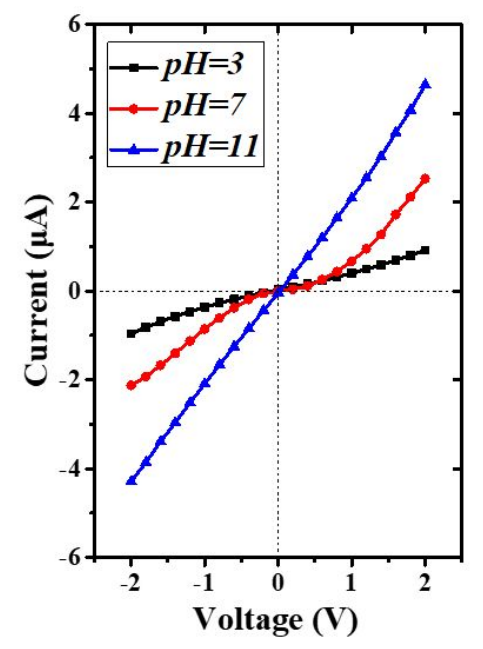

Figure S2. I-V curves of PET cylindrical porous membranes in $\mathrm{pH} 3, \mathrm{pH} 7$ and $\mathrm{pH} 110.1 \mathrm{M} \mathrm{KCl}$ solutions.

With the increasing $\mathrm{pH}$ value of $0.1 \mathrm{M} \mathrm{KCl}$ solution, the Zeta potential of PET membranes became negative and the absolute value increases, which indicated that the pore wall surface of the PET porous membrane is negatively charged under the test environment of this study $(\mathrm{pH}$ $7 \mathrm{KCl}$ solution). Their I-V curves performed higher ion response current under neutral and alkaline conditions, and lower ion response current under acidic conditions. This indicates that this nanochannel could select more cations through the PET membranes at a higher negative surface charge density. 


\section{The estimated surface-charge density of 1D PET nanochannels by conductance in figure}

2c

We have estimated the surface charge density of PET membranes from the conductance measurements in figure $2 \mathrm{c}$ by equation $\mathrm{r} 1^{\mathrm{s} 1, \mathrm{~s} 2}$ :

$G=\kappa_{b}\left(\frac{4 L}{\pi d^{2}} \times \frac{1}{1+4 \frac{{ }^{1} D_{u}}{d}}+\frac{2}{\alpha d+\beta 1_{D_{u}}}\right)^{-1} \mathrm{~S} 1$

where where $\kappa_{b}$ is the bulk conductivity, $L$ is the channel length, $\mathrm{d}$ is the channel diameter, $l_{D u}$ is the Dukhin length (which can be approximated by $\frac{|\Sigma| / e}{2 c_{s}}$, where $e$ is the elementary charge and $c_{s}$ is the salt concentration), $\alpha$ is a geometrical prefactor that depends on the model and $\beta$ can also be approximated to be 2 to obtain the best fitting agreement. In this equation, the second term accounts for the entrance effect. For long nanochannels with $\mathrm{L} \gg d$, this term was neglected to simplified calculation ${ }^{\mathrm{s} 3}$. According to the calculation, the surface charge density of PET channel was approximated to be $0.005-0.012 \mathrm{C} / \mathrm{m}^{2}$. In our simulation for this research, the surface-charge density was set as $0.01 \mathrm{C} / \mathrm{m}^{2}$ to accord with the experimental test. 


\section{The properties of channel $1 \& 2$ bi-channel system.}

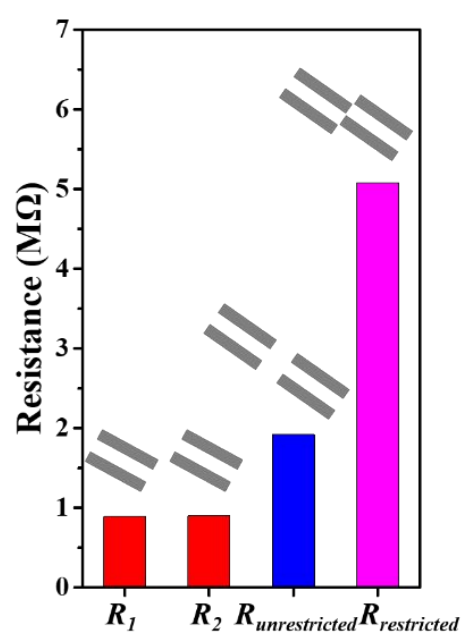

Figure S3. The resistance value of the channel 1, channel 2, restricted bi-channel and unrestricted bi-channel cascade modes.
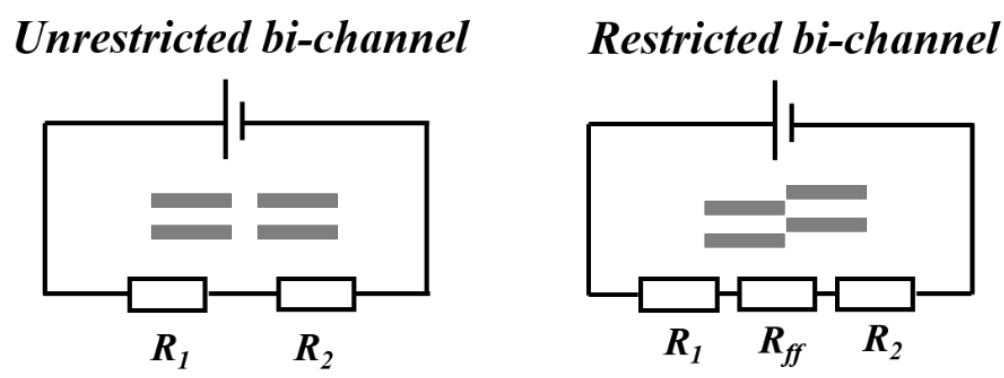

Figure S4. Equivalent circuit diagram of bi-channel system cascaded in restricted and unrestricted modes

In unrestricted bi-channel system, the two channel units transport ions independently. The total resistance of the system was the sum of two channel units $\left(R_{1}\right.$ and $\left.R_{2}\right)$. So, its total conductance was $\frac{1}{R_{1}+R_{2}}$. In restricted bi-channel system, there was field focusing resistance $\left(R_{f f}\right)$ existed within channel units confinement gaps. Therefore, the total resistance of the system was the sum of $R_{1}, R_{2}$ and $R_{f f}$, and its total conductance was $\frac{1}{R_{1}+R_{2}+R_{f f}}$. The mechanism of $R_{f f}$ formation has been fully reported ${ }^{\mathrm{S} 4}$. 
3. The supplymentary ionic transport behavior of channel $1 \& 3$ system in constant concentration solution.

Caculation model of channel $1 \& 3$ mode in constant concentration solution $(10 \mathrm{mM}$ $\mathrm{KCl})$.

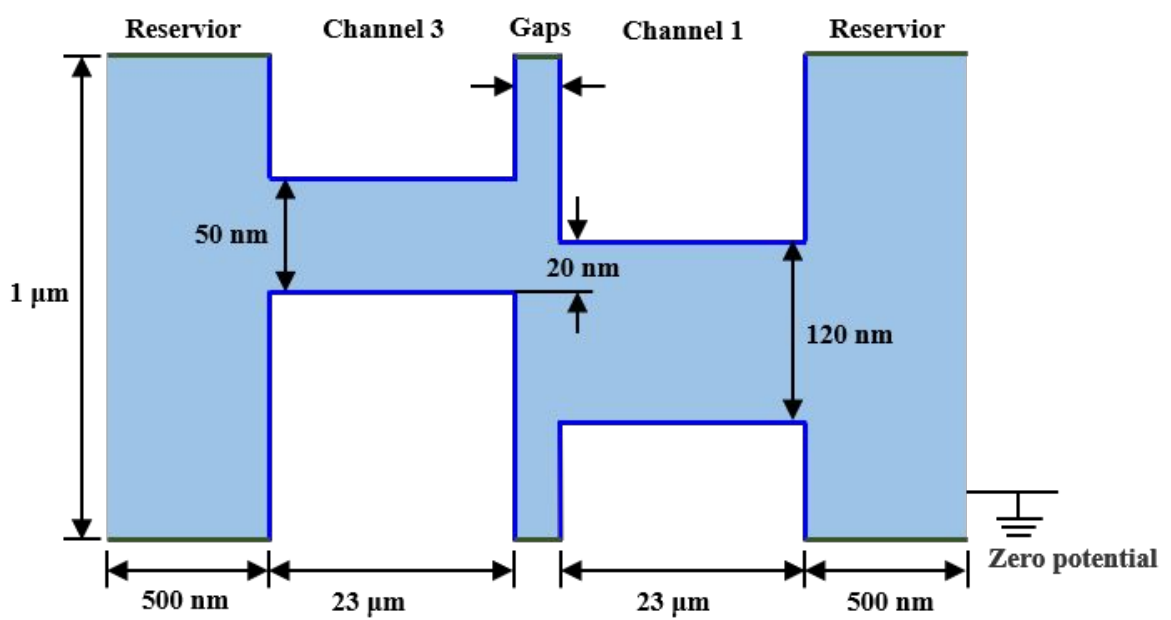

Figure S5. Caculation model of channel $1 \& 3$ mode in constant concentration solution $(10 \mathrm{mM}$ $\mathrm{KCl}$ ). The surface charge density of the channel units was setted as $0.01 \mathrm{C} / \mathrm{m}^{2}$ (refers to the surface charge density of PET porous membranes in $\mathrm{pH} 7$, as the blue line shown), There was no material exchange at the set boundary (the blue and green line). Zero potential was setted as the right boundary. 
The simulated ionic concentration distribution and I-V curves of channel $1 \& 3$ restricted mode.

a)

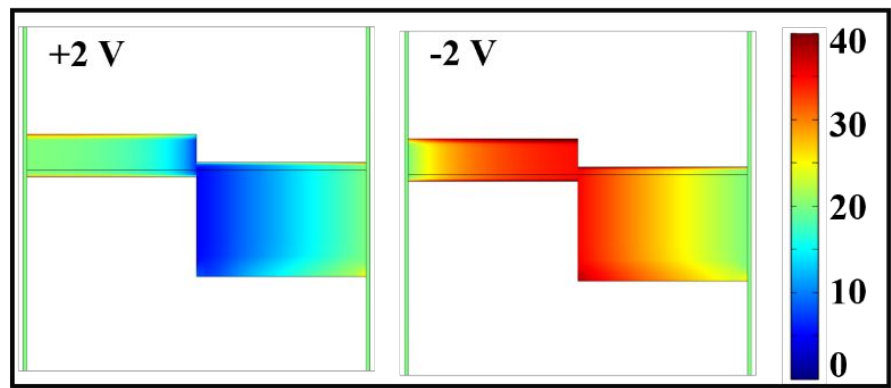

b)

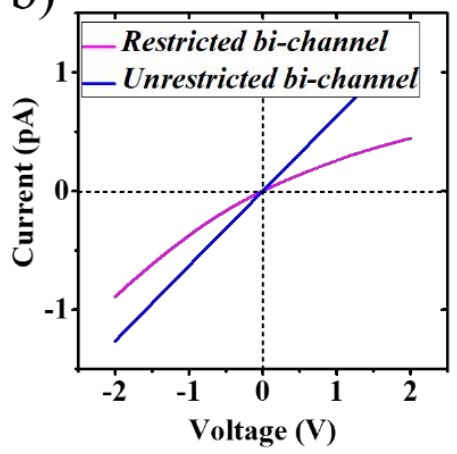

Figure S6. (a) Numerical simulation of ion concentration distribution $\left(C_{p}+C_{n}, \mathrm{mM}\right)$ profiles of channel $1 \& 3$ restricted mode at -2 and $+2 \mathrm{~V}$ bias, which indicated that the ions could be enriched or depleted at stacking interfaces. (b) Numerical simulated I-V curves of channel $1 \& 3$ restricted and unrestricted cascade mode, which were accorded with the trend of experimental tested I-V curves. 
The simulated I-V curves, rectification ratio, cations transfer numbers $\left(t_{p}\right)$ and $C_{p} / C_{\text {total }}$ with different gap width.

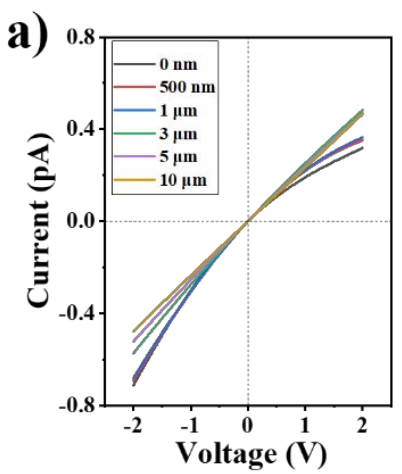

b)

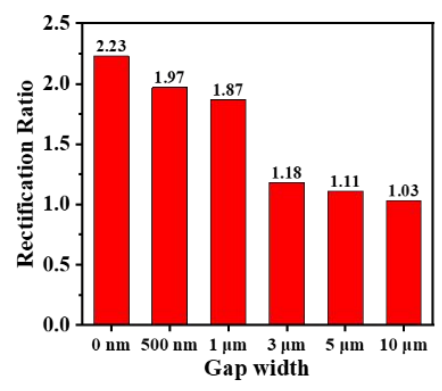

c)

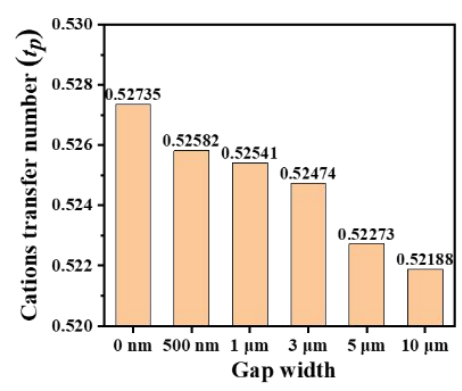

d)

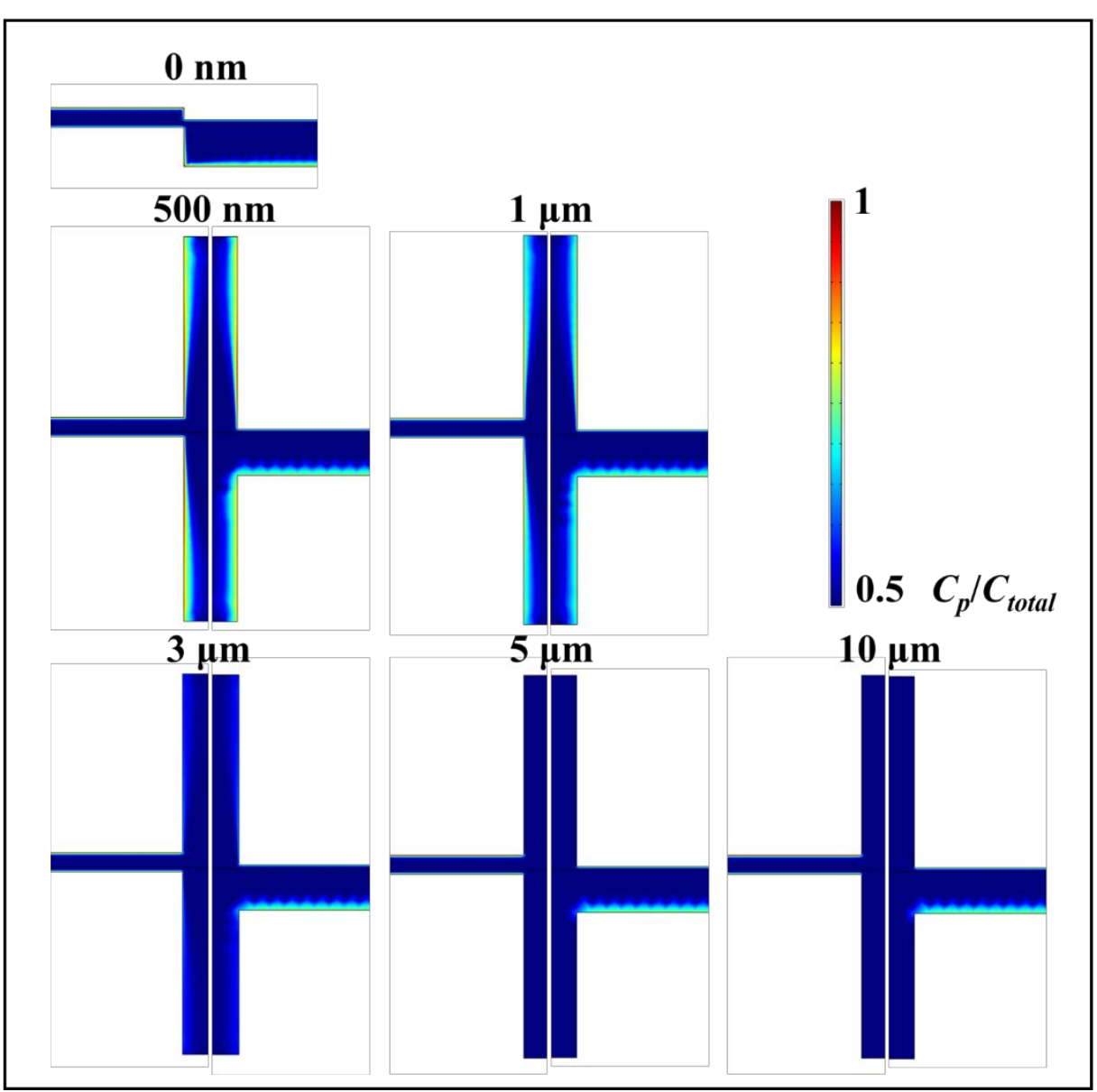

Figure S7. The numerical simulated (a) I-V curves, (b) rectification ratio, (c) cations transfer numbers $\left(t_{p}\right)$ and $(\mathrm{d})$ cations concentration ratio $\left(C_{p} / C_{\text {total }}\right)$ of channel $1 \& 3$ system with different gap width. $C_{p} / C_{\text {total }}$ was obtained under $0 \mathrm{~V}$ bias, and to display the concentration at the correct aspect ratio, a portion of the concentration within the gaps were omitted. 
4. The supplymentary ionic transport behavior of channel $1 \& 2$ system in salinity gradient solution.

4.1 The experimental tested data of channel $1 \& 2$ mode in salinity gradient solutions.

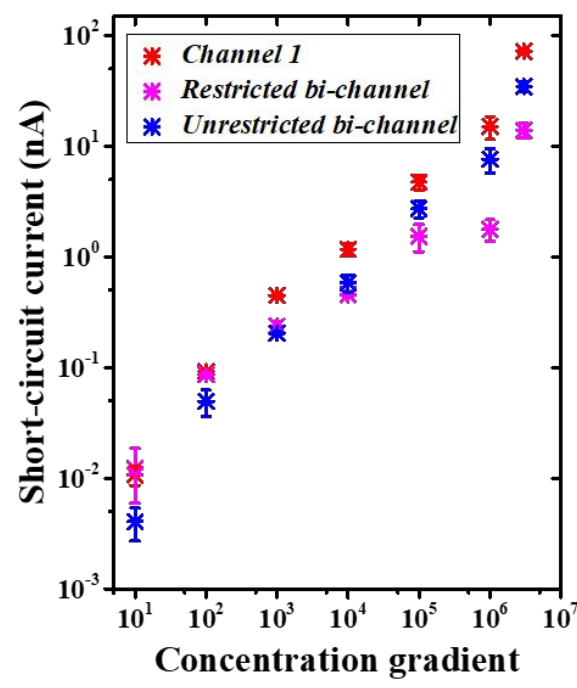

Figure S8. The experimental tested short-circuit current $\left(I_{s c}\right)$ of the channel $1 \& 2$ mode varies with the salinity gradient. The low concentration was fixed as $1 \mu \mathrm{M} \mathrm{KCl}$, and the high concentration was range from $10 \mu \mathrm{M}$ to $3 \mathrm{M}$. 
Table S2. The measured parameters of channel $1 \& 2$ mode in salinity gradient solutions.

\begin{tabular}{|c|c|c|c|c|c|c|c|c|c|}
\hline $\begin{array}{c}\text { Salinity } \\
\text { gradient } \\
(\mathrm{M} / \mathrm{M})\end{array}$ & Channel & $\begin{array}{c}U_{O C} \\
(\mathbf{m V})\end{array}$ & $\begin{array}{c}I_{S C} \\
(\mathbf{n A})\end{array}$ & $\begin{array}{l}E_{\text {redox }} \\
(\mathrm{mV})\end{array}$ & $\begin{array}{c}E_{E P} \\
(\mathbf{m V})\end{array}$ & $\begin{array}{c}E_{\text {Diff }} \\
(\mathrm{mV})\end{array}$ & $r(\mathrm{M} \Omega)$ & $t_{p}$ & $\begin{array}{c}\eta_{w} \\
(\%)\end{array}$ \\
\hline \multirow{3}{*}{$10^{-6} / 10^{-5}$} & 1 & 51.96 & 0.0107 & \multirow{3}{*}{59.12} & \multirow{3}{*}{41.01} & 10.96 & 4874.55 & 0.5927 & 1.72 \\
\hline & $1 \& 2 \mathrm{STA}$ & 93.84 & 0.0123 & & & 52.84 & 9161.68 & 0.9469 & 39.94 \\
\hline & $1 \& 2 \mathrm{SEP}$ & 59.27 & 0.0041 & & & 18.27 & 10141.35 & 0.6545 & 4.78 \\
\hline \multirow{3}{*}{$10^{-6} / 10^{-4}$} & 1 & 87.04 & 0.0921 & \multirow{3}{*}{118.25} & \multirow{3}{*}{72.16} & 15.04 & 942.86 & 0.5636 & 0.81 \\
\hline & $1 \& 2 \mathrm{STA}$ & 171.82 & 0.0865 & & & 99.82 & 1994.52 & 0.9221 & 35.63 \\
\hline & $1 \& 2 \mathrm{SEP}$ & 103.04 & 0.0494 & & & 31.04 & 2112.56 & 0.6312 & 3.45 \\
\hline \multirow{3}{*}{$10^{-6} / 10^{-3}$} & 1 & 196.93 & 0.4483 & \multirow{3}{*}{176.46} & \multirow{3}{*}{159.04} & 37.93 & 438.89 & 0.6075 & 2.31 \\
\hline & $1 \& 2 \mathrm{STA}$ & 323.79 & 0.2370 & & & 164.79 & 1369.15 & 0.9669 & 43.61 \\
\hline & $1 \& 2$ SEP & 228.64 & 0.2039 & & & 69.64 & 1124.54 & 0.6973 & 7.79 \\
\hline \multirow{3}{*}{$10^{-6} / 10^{-2}$} & 1 & 220.97 & 1.1725 & \multirow{3}{*}{233.83} & \multirow{3}{*}{153.11} & 67.97 & 188.38 & 0.6453 & 4.22 \\
\hline & $1 \& 2 \mathrm{STA}$ & 361.48 & 0.4553 & & & 208.48 & 796.31 & 0.9458 & 39.75 \\
\hline & $1 \& 2 \mathrm{SEP}$ & 285.55 & 0.5850 & & & 132.55 & 503.90 & 0.7834 & 16.07 \\
\hline \multirow{3}{*}{$10^{-6} / 10^{-1}$} & 1 & 269.20 & 4.7240 & \multirow{3}{*}{289.58} & \multirow{3}{*}{181.01} & 88.20 & 57.17 & 0.6523 & 4.64 \\
\hline & $1 \& 2 \mathrm{STA}$ & 439.24 & 1.5338 & & & 258.24 & 296.07 & 0.9459 & 39.76 \\
\hline & $1 \& 2$ SEP & 368.20 & 2.7258 & & & 187.20 & 138.03 & 0.8232 & 20.90 \\
\hline \multirow{3}{*}{$10^{-6 / 1}$} & 1 & 310.85 & 14.9891 & \multirow{3}{*}{341.89} & \multirow{3}{*}{193.96} & 116.85 & 21.62 & 0.6709 & 5.84 \\
\hline & $1 \& 2 \mathrm{STA}$ & 452.07 & 1.7773 & & & 258.07 & 258.38 & 0.8774 & 28.49 \\
\hline & $1 \& 2 \mathrm{SEP}$ & 401.12 & 2.6241 & & & 207.12 & 53.57 & 0.8029 & 18.35 \\
\hline \multirow{3}{*}{$10^{-6 / 3}$} & 1 & 316.33 & 72.0375 & \multirow{3}{*}{368.58} & \multirow{3}{*}{211.06} & 105.33 & 4.38 & 0.6429 & 4.08 \\
\hline & $1 \& 2 \mathrm{STA}$ & 459.17 & 13.9121 & & & 248.17 & 33.36 & 0.8367 & 22.67 \\
\hline & $1 \& 2$ SEP & 427.82 & 34.5045 & & & 216.82 & 12.51 & 0.7942 & 17.30 \\
\hline $\begin{array}{c}\text { Data in } \\
\text { manuscript }\end{array}$ & - & Fig. 5c & Fig. S8 & - & - & - & Fig. 5d & - & Fig. $5 \mathrm{e}$ \\
\hline
\end{tabular}




\subsection{Numerical simulated parameters of channel $1 \& 2$ mode in salinity gradient solution}

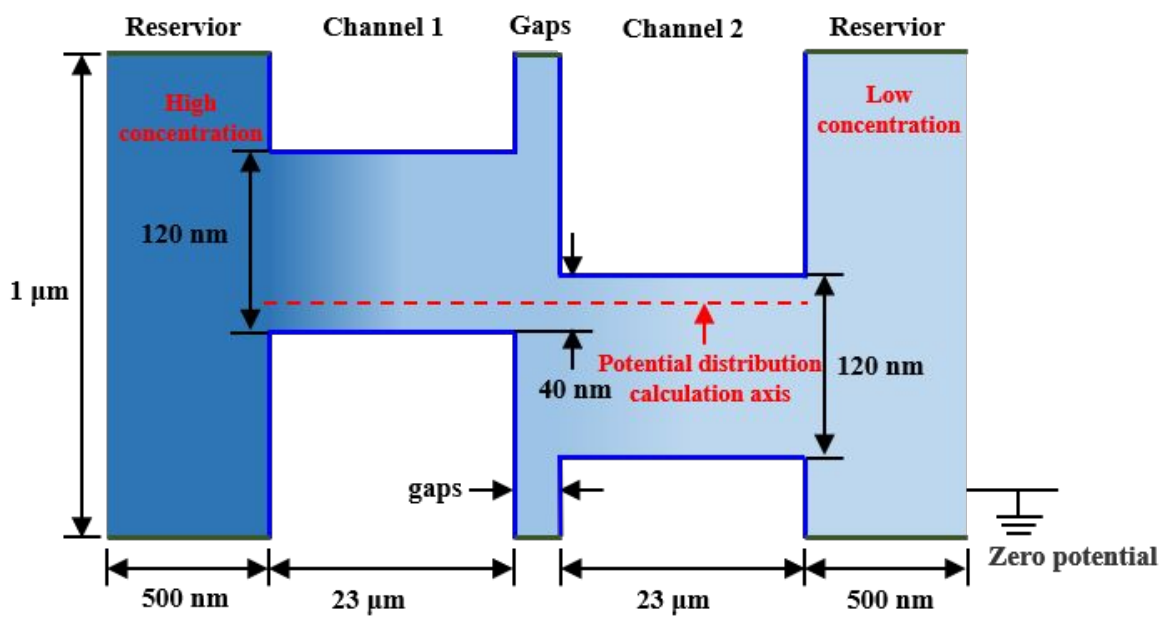

Figure S9. Caculation model of channel $1 \& 2$ mode in salinity gradient solution $(100 \mathrm{mM} / 1$ $\mathrm{mM} \mathrm{KCl}$ ). The surface charge density of the channel units was setted as $0.01 \mathrm{C} / \mathrm{m}^{2}$ (refers to the surface charge density of PET porous membranes in $\mathrm{pH} 7$, as the blue line shown), There was no material exchange at the set boundary (the blue and green line). Zero potential was setted as the right boundary. The diffusion potential distribution was calculated at figure S10 along the dotted red line.

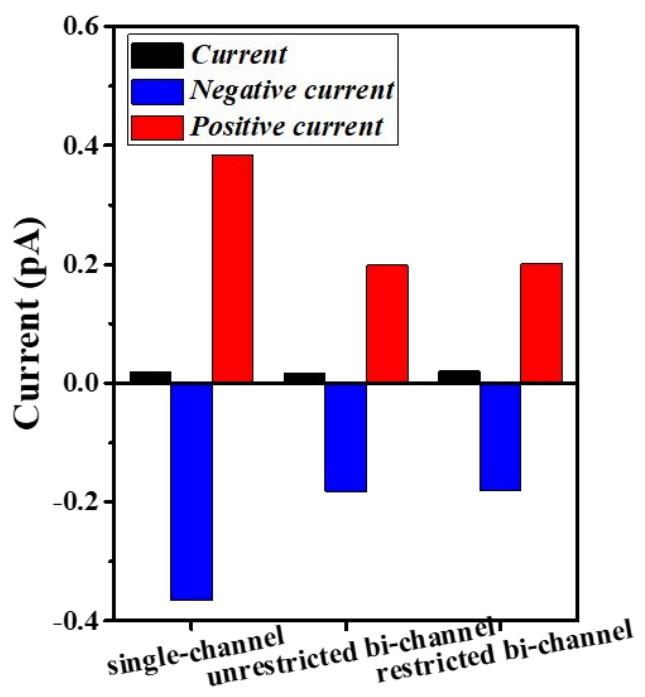

Figure S10. The nunerical simulated cations and anions contribution current in single-channel, unrestricted bi-channel and restricted bi-channel modes. The cation migration number $\left(t_{p}\right)$ 
presented in figure $4 \mathrm{f}$ was calculated by $t_{p}=I_{+} /\left(\left|I_{+}\right|+\left|I_{-}\right|\right), I_{+}$was the cations contribution current and $I_{-}$was the anions contribution current. The salinity gradient was setting as $100 \mathrm{mM} / 1 \mathrm{mM}$.

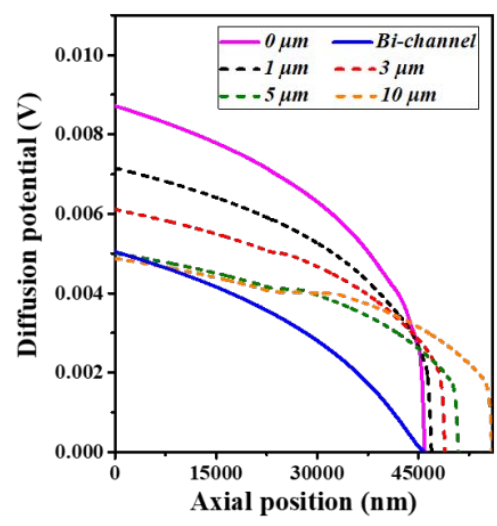

Figure S11. The numerical simulation of axial diffusion potential distribution of bi-channel systems with different stacking gaps. The salinity gradient was setting as $0.1 \mathrm{M} / 1 \mathrm{mM}$.

The gaps effects on diffusion potential of restricted bi-channel mode in salinity gradient solutions was discussed. As shown in figure S10, the stacking bi-channel system without gaps (pink solid line) performed higher diffusion potential $\left(E_{d i f f}\right)$. As the gap widens, $E_{\text {diff }}$ was decreacing gradually and close to the bi-channel system without confinement effects (blue solid line). When the gaps were larger than $5 \mu \mathrm{m}$, the bi-channel systems performed steady $E_{\text {diff. }}$
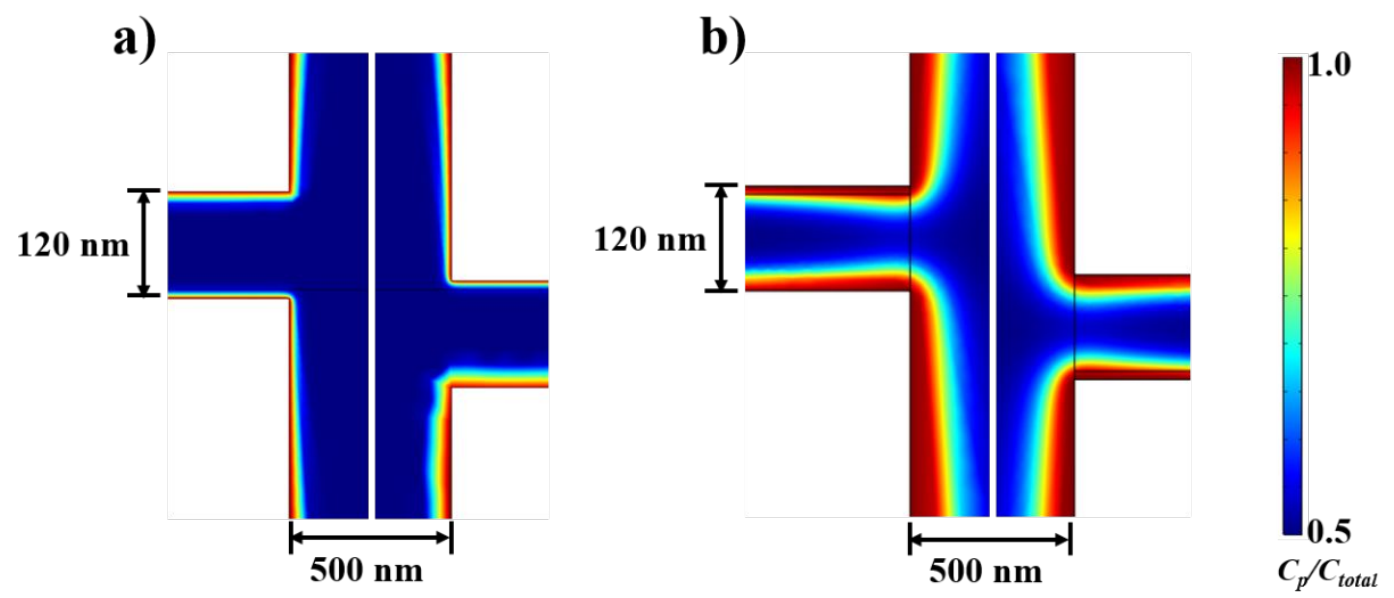

Figure S12. The numerical simulated cations concentration ratio $\left(C_{p} / C_{\text {total }}\right)$ of channel $1 \& 2$ system with (a) $10 \mathrm{mM} / 0.1 \mathrm{mM} \mathrm{KCl}$ and (b) $0.1 \mathrm{mM} / 0.001 \mathrm{mM} \mathrm{KCl}$ concentration gradient (gap width was set at $500 \mathrm{~nm}$; surface charge density was set as $0.01 \mathrm{C} / \mathrm{m}^{2}$ ). 
As shown in figure S12, with the influence of gap confinement effects, electric double layer (EDL) thickness will be increased by the electric field line mutation at the gap pore walls. Its thickness could be increased to tens of nanometers, which matches the pore size and improve the cations transfer numbers of the system. When more channel units were connected in tandem, the gaps will perform significant EDL thickening phenomenon in the low concentration region, which will enhance the surface charge governed behavior and cation selectivity of the system. 

artificial seawater and river water solutions.

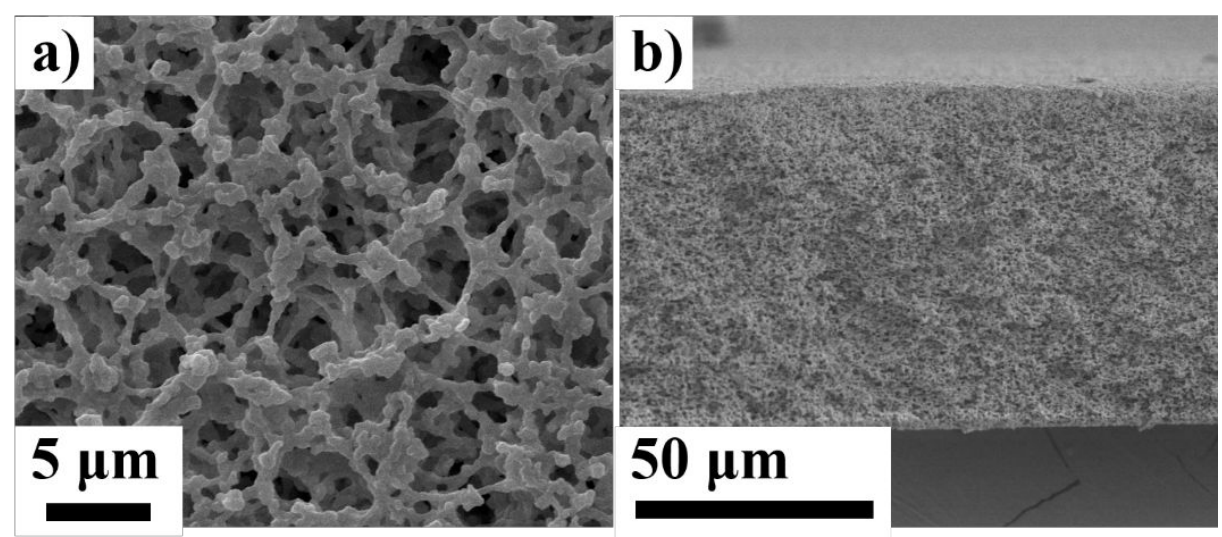

Figure S13. Geometrical parameters of the cellulose acetate membranes (CAM). The SEM images of cellulose acetate membranes (CAM). (a) surface view (pore size was $100 \mathrm{~nm}$ ); (b) cross-section view ( $\sim 85 \mu \mathrm{m}$ in thickness).

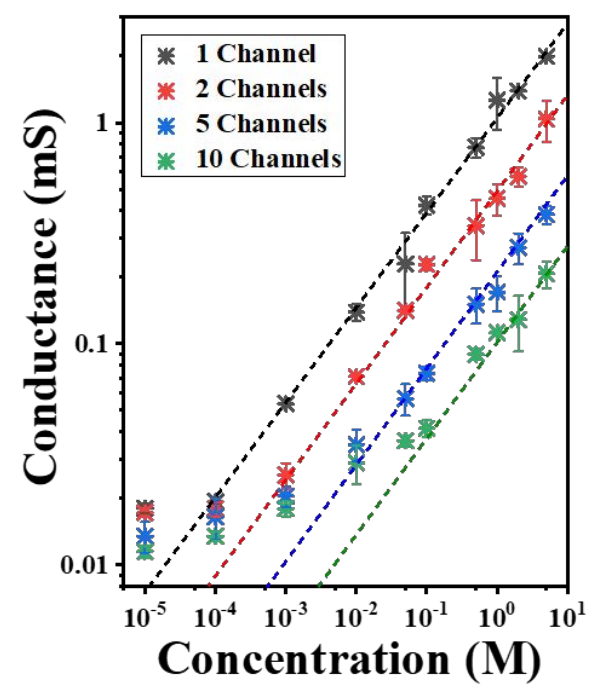

Figure S14. The CAM channel system transmembrane ionic conductance at different concentration. Conductance apparently deviates from bulk value below $\sim 0.01 \mathrm{mM}$ in 1 channel unit, below $\sim 0.1 \mathrm{mM}$ in tandem 2 channel units, below $10 \mathrm{mM}$ in tandem 5 channel units and below $50 \mathrm{mM}$ in tandem 10 channel units. 
As shown in figure S14, with the increases of channel numbers, the surface-charge governed behavior was appeared at high concentration, which indicated that the gap confinements between channel units could enhance the surface charge governed capacity of the system.

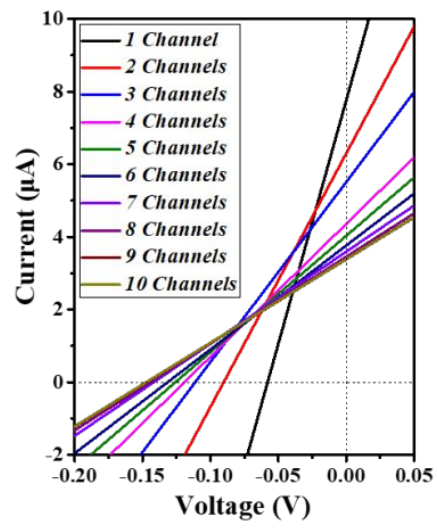

Figure S15. I-V curves of a serials of channel numbers in artificial seawater and river water solutions $(0.5 \mathrm{M} / 0.01 \mathrm{M} \mathrm{NaCl})$. The testing voltage was from -0.2 to $0.2 \mathrm{~V}$.

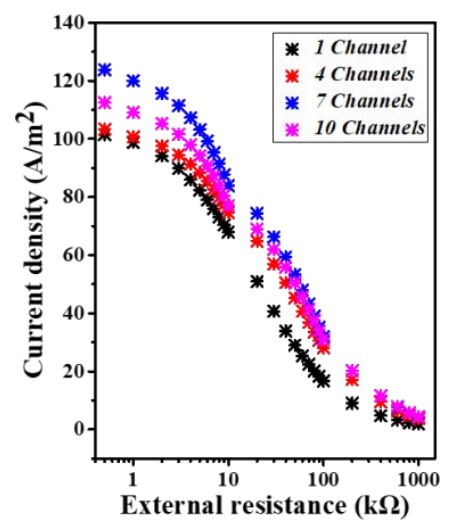

Figure S16. The tandem CAM nanochannel system current density with a serials of external resistance with diffenrent channel numbers. The tested data was obtained in artificial seawater and river water solutions $(0.5 \mathrm{M} / 0.01 \mathrm{M} \mathrm{NaCl})$. 
Table S3. The measured parameters of tandem CAM system in artificial sea water and river water solutions.

\begin{tabular}{cccccccccc}
\hline $\begin{array}{c}\text { Channel } \\
\text { numbers }\end{array}$ & $\begin{array}{c}\boldsymbol{U}_{\boldsymbol{O}} \\
(\mathbf{m V})\end{array}$ & $\begin{array}{c}\boldsymbol{I}_{\boldsymbol{S C}} \\
(\boldsymbol{\mu A})\end{array}$ & $\begin{array}{c}\boldsymbol{E}_{\text {redox }} \\
(\mathbf{m V})\end{array}$ & $\begin{array}{c}\boldsymbol{E}_{\boldsymbol{E} \boldsymbol{P}} \\
(\mathbf{m V})\end{array}$ & $\begin{array}{c}\boldsymbol{E}_{\boldsymbol{D} \text { iff }} \\
(\mathbf{m V})\end{array}$ & $\begin{array}{c}\boldsymbol{r} \\
(\mathbf{k} \boldsymbol{\Omega})\end{array}$ & $\boldsymbol{t}_{\boldsymbol{p}}$ & $\begin{array}{c}\boldsymbol{\eta}_{\boldsymbol{w}} \\
(\mathbf{\%})\end{array}$ & $\begin{array}{c}\boldsymbol{P}_{\max } \\
\left(\mathbf{W} / \mathbf{m}^{2}\right)\end{array}$ \\
\hline 1.00 & 57.90 & 4.32 & & & 1.78 & 7.46 & 0.51 & 0.02 & 1.37 \\
2.00 & 90.24 & 2.52 & & & 34.12 & 14.34 & 0.68 & 6.71 & 1.89 \\
3.00 & 111.16 & 2.20 & & & 55.04 & 20.18 & 0.80 & 17.46 & 2.04 \\
4.00 & 119.12 & 1.74 & & & 63.00 & 27.36 & 0.84 & 22.88 & 3.38 \\
5.00 & 125.74 & 1.61 & 93.14 & 56.12 & 69.62 & 31.25 & 0.87 & 27.94 & 3.80 \\
6.00 & 131.47 & 1.51 & & & 75.35 & 34.96 & 0.90 & 32.73 & 4.22 \\
7.00 & 141.70 & 1.38 & & & 85.58 & 39.87 & 0.96 & 42.22 & 4.72 \\
8.00 & 144.56 & 1.28 & & & 90.75 & 43.41 & 0.99 & 47.47 & 4.15 \\
9.00 & 146.87 & 1.25 & & & 91.02 & 43.40 & 0.99 & 47.75 & 3.92 \\
10.00 & 147.14 & 1.26 & & - & - & Fig. 6c & - & Fig. 6e & Fig. 6f \\
\hline $\begin{array}{c}\text { Data in } \\
\text { manuscript }\end{array}$ & Fig. 6b & Fig. 6b & - & - & - & & &
\end{tabular}




\section{The ionic transport behavior of tandem PET system in artificial seawater and river}

water solutions.

a)

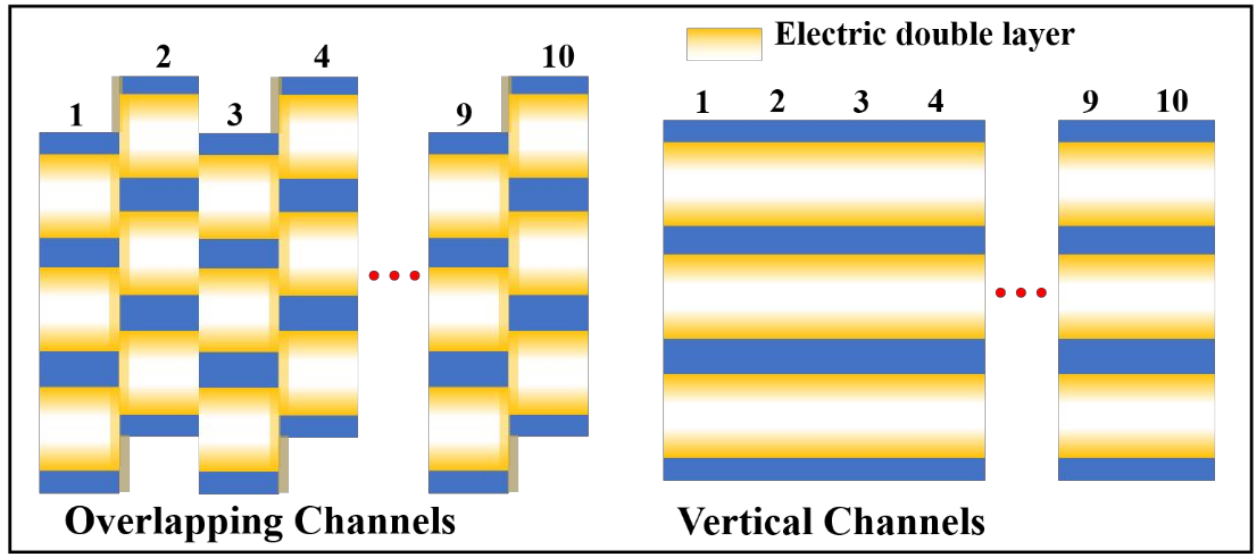

b)

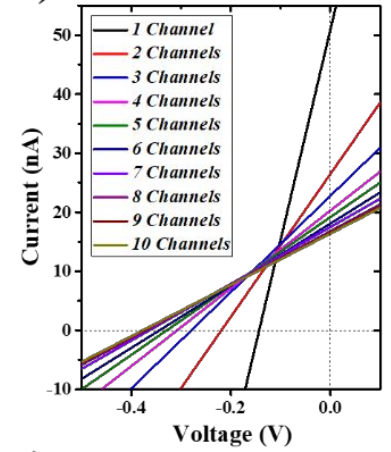

e)

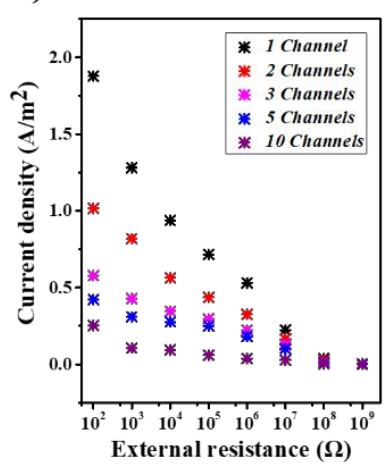

c)

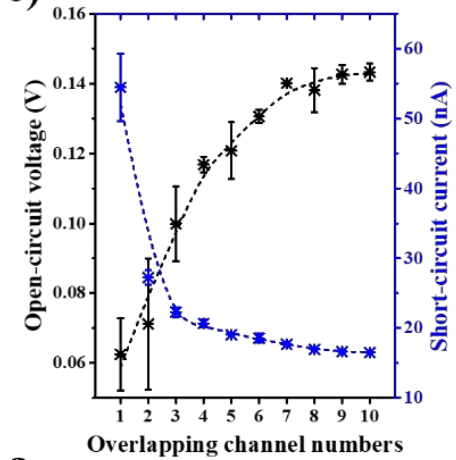

f)

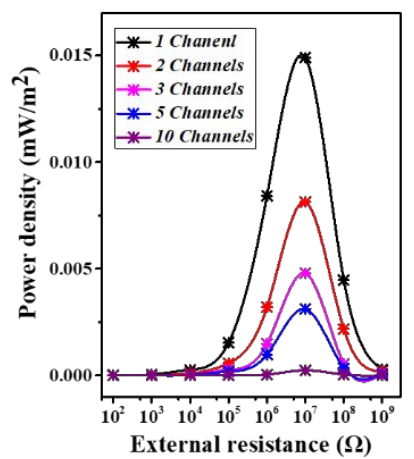

d)

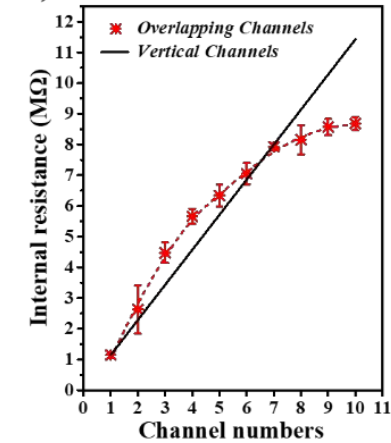

g)

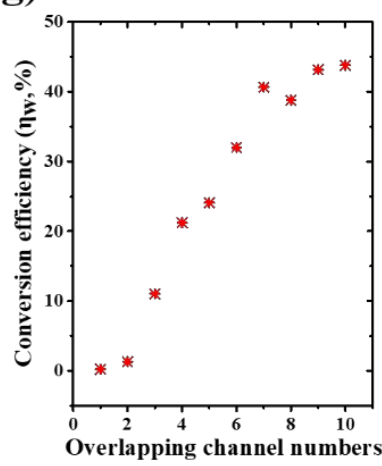

Figure S17. (a) The schematic of tandem PET channel systems, the stacking channel numbers were range from 1 to 10 . (b) I-V curves of a serials of channel numbers in artificial seawater and river water solutions $(0.5 \mathrm{M} / 0.01 \mathrm{M} \mathrm{NaCl})$. The testing voltage was from -0.2 to $0.2 \mathrm{~V}$. (c) The $I_{S C}, U_{O C}$ and (d) internal resistance $(r)$ measured in a series of channel numbers. The (e) current density and (f) external power density output by electronic load in a series of channel 
numbers $(1,2,3,5$, and 10$)$ in artificial seawater $(0.5 \mathrm{M} \mathrm{NaCl})$ and river water $(0.01 \mathrm{M} \mathrm{NaCl})$ salinity gradient solutions. (g) The power generation efficiency with a serials of channel number (1 to 10$)$. (f) The maximum power generation efficiency $\left(\eta_{w}\right)$ was $43.79 \%$.

Table S4. The measured parameters of tandem PET channel systems in artificial sea water and river water solutions.

\begin{tabular}{cccccccccc}
\hline $\begin{array}{c}\text { Channel } \\
\text { numbers }\end{array}$ & $\begin{array}{c}\boldsymbol{U}_{\boldsymbol{O}} \\
(\mathbf{m V})\end{array}$ & $\begin{array}{c}\boldsymbol{I}_{\boldsymbol{S C}} \\
(\mathbf{n A})\end{array}$ & $\begin{array}{c}\boldsymbol{E}_{\text {redox }} \\
(\mathbf{m V})\end{array}$ & $\begin{array}{c}\boldsymbol{E}_{\boldsymbol{E} \boldsymbol{P}} \\
(\mathbf{m V})\end{array}$ & $\begin{array}{c}\boldsymbol{E}_{\text {Diff }} \\
(\mathbf{m V})\end{array}$ & $\boldsymbol{r} \mathbf{( \mathbf { M } \mathbf { ) } )}$ & $\boldsymbol{t}_{\boldsymbol{p}}$ & $\boldsymbol{\eta}_{\boldsymbol{w}}(\mathbf{\%})$ & $\begin{array}{c}\boldsymbol{P}_{\max } \\
\left(\mathbf{m W} / \mathbf{m}^{\mathbf{2}}\right)\end{array}$ \\
\hline 1 & 62.46 & 54.46 & & & 6.35 & 1.14 & 0.5341 & 0.23 & 14.9040 \\
2 & 71.19 & 27.24 & & & 15.07 & 2.63 & 0.5809 & 1.31 & 8.1402 \\
3 & 99.86 & 22.29 & & & 43.74 & 4.47 & 0.7348 & 11.03 & 4.7918 \\
4 & 116.83 & 20.64 & & & 60.71 & 5.66 & 0.8259 & 21.24 & 4.3368 \\
5 & 120.77 & 19.04 & 93.14 & 56.12 & 64.65 & 6.34 & 0.8471 & 24.09 & 3.1182 \\
6 & 130.62 & 18.53 & & & 74.50 & 7.05 & 0.9000 & 31.99 & 0.5513 \\
7 & 140.12 & 17.68 & & & 84.00 & 7.93 & 0.9509 & 40.67 & 0.3781 \\
8 & 138.16 & 16.95 & & & 86.55 & 8.15 & 0.9404 & 38.79 & 0.3198 \\
9 & 142.67 & 16.65 & & & 87.21 & 8.68 & 0.9679 & 43.79 & 0.2375 \\
10 & 143.29 & 16.50 & & - & - & Fig. S17d & - & Fig. S17f & Fig. S17g \\
\hline $\begin{array}{c}\text { Data in } \\
\text { manuscript }\end{array}$ & Fig. S17c & Fig. S17c & - & - & & & & &
\end{tabular}

In tandem PET channel systems, due to the low porosity, the ions flux was significantly reduced when multistage channel units were stacked. As a result, its output current density was reduced, although the system achieves $43.79 \%$ power generation efficiency, its output power was only $0.2375 \mathrm{~mW} / \mathrm{m}^{2}$ 
7.The time dependent power generation behavior with CAM tandem system

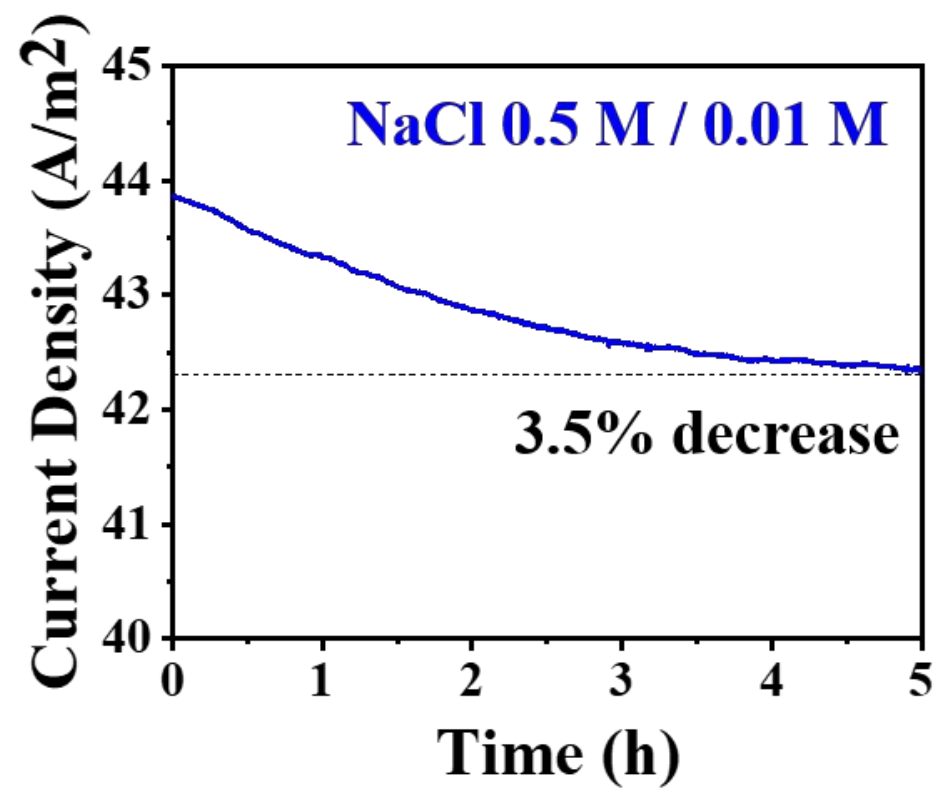

Figure S18. Current density-time curve of CAM channel system with 10 cascade numbers without electrolyte replenishing. 


\section{The electrical measurement}

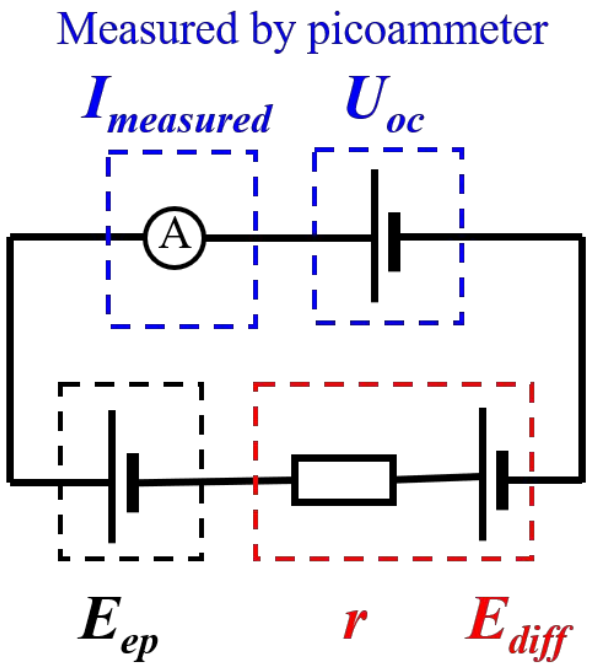

The electrode potential measured experimentally

$$
E_{\text {diff }}=U_{o c}-E_{e p}
$$

Figure S19. Equivalent circuit diagram of salinity gradient power generation systems.

In the salinity gradient power generation systems, the total potential $\left(U_{o c}\right)$ measured by picoammeter consisted of the electrode potential $\left(E_{e p}\right)$ generated by $\mathrm{Ag} / \mathrm{AgCl}$ electrodes and diffusion potential $\left(E_{\text {diff }}\right)$ generated by ion selective membranes ${ }^{\mathrm{s} 5}$. Due to the influence of the superpotential and the polarization potential at the interface between the electrode and the solution, the tested value of electrode potential $\left(E_{e p}\right)$ was less than that of redox potential $\left(E_{\text {redox }}\right)$. Here, $E_{e p}$ was measured by separation the two chambers by non-selective silicon membrane containing a single micro-window (transparent area was $\sim 3 \times 10^{4} \mu \mathrm{m}^{2}$ ).

$E_{\text {redox }}$ was calculated by

$E_{\text {redox }}=\frac{R T}{z F} \ln \frac{a_{\text {high }}}{a_{\text {low }}}$

$R$ was the ideal gas constant, $T$ was the absolute temperature, $F$ was the Faraday ‘s constant, $z$ was the ionic absolute value of the valence state, $a_{h i g h}$ and $a_{l o w}$ were high and low concentration ion activities respectively.

$E_{\text {diff }}$ was calculated by

$E_{\text {diff }}=U_{o c}-E_{e p}$ 
The internal resistances $(r)$ of the multi-channel systems was calculated by

$r=\frac{U_{o c}}{I_{s c}}$

When external load resistor was present, the current density $\left(I_{\text {density }}\right)$ of the system was calculated by

$I_{\text {density }}=\frac{I}{S}$

$I$ was the current of the system measured by picoammeters, $S$ was the tested area of the membranes which was $3 \times 10^{4} \mu \mathrm{m}^{2}$.

The output power density $(P)$ was calculated by

$P=\frac{R I^{2}}{S}$

$I$ was the current of the system measured by picoammeters, $S$ was the tested area of the membranes which was $3 \times 10^{4} \mu \mathrm{m}^{2}$, and $R$ was the external resistance.

The cation migration number $\left(t_{p}\right)$ was calculated by

$2 t_{p}-1=\frac{E_{\text {diff }}}{E_{\text {redox }}}$

The energy conversion efficiency $\left(\eta_{w}\right)$ corresponding to the maximum power generation was calculated by

$\eta_{\mathrm{w}}=\frac{\left(2 t_{p}-1\right)^{2}}{2}$ 


\section{The description of PNP equations ${ }^{\mathrm{S} 6}$.}

The ionic transport behaviors of bi-channel systems could be qualitatively supported by numerical simulation on the basis of Poisson-Nernst-Plank (PNP) equations with COMSOL Multiphysics ${ }^{\circledR}$. The Nernst-Plank equation (S8) describes the transport properties of changed nanochannels, The diffusion coefficient $D_{+}=1.95 \times 10^{-5} \mathrm{~cm}^{2} / \mathrm{s}, D_{-}=2.03 \times 10^{-5} \mathrm{~cm}^{2} / \mathrm{s}$.

$j_{i}=D_{i}\left(\nabla c_{i}+Z_{i} F c_{i} / R T \times \nabla \varphi\right)$

ji, Di, ci, zi, and $\varphi$ are the ionic flux, diffusion coefficient, ion concentration, and valence number for each species $i$ and the electrical potential, respectively.

$\nabla 2 \varphi=-F / \varepsilon \times \Sigma z_{i} c_{i}$

Poisson equation (S9) describe the electrical potential inside the nanochannel related with the ionic concentration.

$\nabla_{i}=0$

The flux was assumed with steady-state conditions and satisfy time-independent continuity equation (S10) 
10. The optical photograph of testing devices of the restricted mode and unrestricted mode
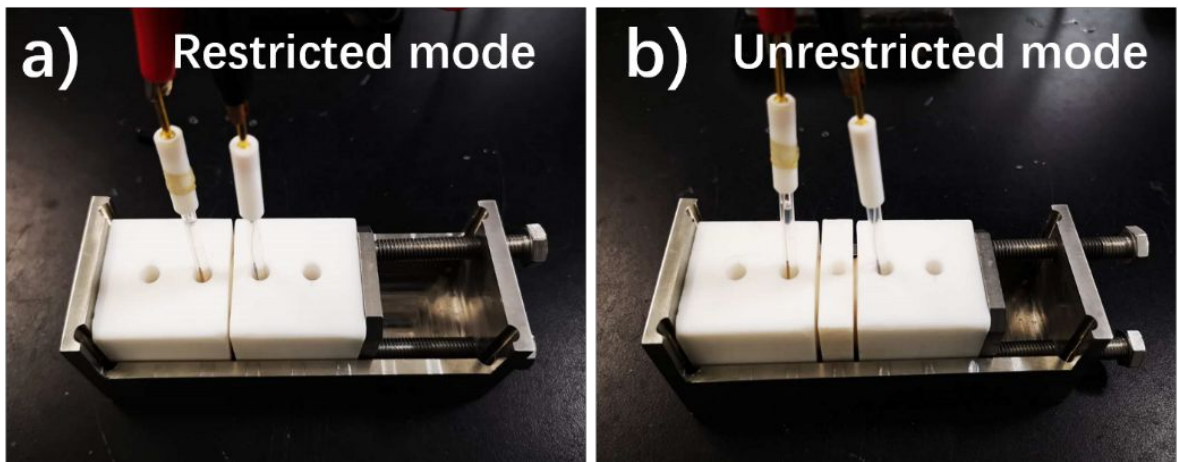

Figure S20. The optical photograph of a) restricted mode and b) unrestricted mode testing devices. 
11. A comparison table with the reported power density existing in literatures.

Table S5. The references about artificial nanochannel system applicated in salinity gradient power generation system in recent years.

\begin{tabular}{ccccc}
\hline Nanochannels & Salinity Gradient & $P_{\max }\left(\mathrm{W} / \mathrm{m}^{2}\right)$ & $\eta_{w}(\%)$ & Ref. \\
\hline PES-Py/PAEK-HS & $0.5 \mathrm{M} / 0.01 \mathrm{M} \mathrm{NaCl}$ & 2.6 & 35.7 & $\mathrm{~S} 7$ \\
MesoC/MacroA & $0.5 \mathrm{M} / 0.01 \mathrm{M} \mathrm{NaCl}$ & 3.46 & 37.3 & $\mathrm{~S} 8$ \\
PES/SPES & $0.5 \mathrm{M} / 0.001 \mathrm{M} \mathrm{NaCl}$ & 2.48 & -- & $\mathrm{S} 9$ \\
PET/BCP & $0.5 \mathrm{M} / 0.01 \mathrm{M} \mathrm{NaCl}$ & 0.35 & -- & $\mathrm{S} 10$ \\
SNF/AAO & $0.5 \mathrm{M} / 0.01 \mathrm{M} \mathrm{NaCl}$ & 2.86 & -- & $\mathrm{S} 11$ \\
GOM/NRED & $0.5 \mathrm{M} / 0.01 \mathrm{M} \mathrm{NaCl}$ & 0.77 & 36.6 & $\mathrm{~S} 12$ \\
(PSS)MOF/AAO & $0.5 \mathrm{M} / 0.01 \mathrm{M} \mathrm{NaCl}$ & 2.87 & -- & $\mathrm{S} 13$ \\
Nafion/AAO & $0.5 \mathrm{M} / 0.01 \mathrm{M} \mathrm{KCl}$ & 3.15 & -- & $\mathrm{S} 14$ \\
UFSCNM & $0.1 \mathrm{M} / 0.1 \mathrm{mM} \mathrm{KCl}$ & 0.21 & -- & $\mathrm{S} 15$ \\
PPy-A/PPyO & $0.5 \mathrm{M} / 0.01 \mathrm{M} \mathrm{NaCl}$ & 0.087 & -- & $\mathrm{S} 16$ \\
Polymetric/AAO & $0.5 \mathrm{M} / 1 \mathrm{mM} \mathrm{KCl}$ & 2.57 & -- & $\mathrm{S} 17$ \\
Mxene/ANF & $0.6 \mathrm{M} / 4 \mathrm{mM} \mathrm{NaCl}$ & 4.1 & -- & $\mathrm{S} 18$ \\
GO/SNF/GO & $0.5 \mathrm{M} / 0.01 \mathrm{M} \mathrm{NaCl}$ & 5.07 & -- & $\mathrm{S} 19$ \\
BP/GO & $0.6 \mathrm{M} / 4 \mathrm{mM} \mathrm{NaCl}$ & 4.7 & -- & $\mathrm{S} 20$ \\
HEMAP hydrogel & $0.5 \mathrm{M} / 0.01 \mathrm{M} \mathrm{NaCl}$ & 5.38 & -- & $\mathrm{S} 21$ \\
SF & $0.5 \mathrm{M} / 0.01 \mathrm{M} \mathrm{NaCl}$ & 4.06 & -- & $\mathrm{S} 22$ \\
PES-OHIm/PES-SO $3 \mathrm{H}$ & $0.5 \mathrm{M} / 0.01 \mathrm{M} \mathrm{NaCl}$ & 6.2 & -- & $\mathrm{S} 23$ \\
CAM Multistage & $0.5 \mathrm{M} / 0.01 \mathrm{M} \mathrm{NaCl}$ & 4.72 & 42.22 & -- \\
nanochannel & & & &
\end{tabular}




\section{References}

[S1] Feng, J.; Graf, M.; Liu, K.; Ovchinnikov, D.; Dumcenco, D.; Heiranian, M.; Nandigana, V.; Aluru, N. R.; Kis, A.; Radenovic, A. Single-layer $\mathrm{MoS}_{2}$ Nanopores as Nanopower Generators. Nat. 2016, 536, doi:10.1038/nature18593.

[S2] Siria, A.; Poncharal, P.; Biance, A-L.; Fulcrand, R.; Blase, X.; Purcell, S. T.; Bocquet, L. Giant Osmotic Energy Conversion Measured in a Single Transmembrane Boron Nitride Nanotube. Nat. 2013, DOI: $10.1038 /$ nature11876.

[S3] Lee, C.; Joly, L.; Siria, A.; Biance, A-L.; Fulcrand, R.; Bocquet, L. Large Apparent Electric Size of Solid-State Nanopores Due to Spatially Extended Surface Conduction. Nano Lett. 2012, 12, 4037-4044.

[S4] Wang, Y.; Chen, H.; Jiang, J.; Zhai, J.; You, T., Ion Transport Behaviors of Nanofluidic Diode Bichannel Systems in the Independent and Synergistic Cascade Mode. ACS Appl. Mater. Interfaces 2019, 11, 2646726473.

[S5] Su, Y-S.; Hsu, S-C.; Peng, P-H.; Yang, J-Y.; Gao, M.; Yeh, L-H. Unraveling the Anomalous Channellength-dependent Blue Energy Conversion Using Engineered Alumina Nanochannels. Nano Energy 2021, 84,105930 .

[S6] Wang, J.; Zhang, M.; Zhai, J.; Jiang, L., Theoretical Simulation of the Ion Current Rectification (ICR) in Nano-pores Based on the Poisson-Nernst-Planck (PNP) Model. Phys. Chem. Chem. Phys., 2014, 16, $23-$ 32.

[S7] Zhu, X.; Hao, J.; Bao, B.; Zhou, Y.; Zhang, H.; Pang, J.; Jiang, Z.; Jiang, L., Unique Ion Rectification in Hypersaline Environment: A High-performance and Sustainable Power Generator System. Sci. Adv. 2018, 4, eaau1665.

[S8] Gao, J.; Guo, W.; Feng, D.; Wang, H.; Zhao, D.; Jiang, L., High-performance Ionic Diode Membrane for Salinity Gradient Power Generation. J. Am. Chem. Soc. 2014, 136, 12265-12272.

[S9] Huang, X.; Zhang, Zhen.; Kong, X.; Sun, Y.; Zhu, C.; Liu, P.; Pang, J.; Jiang, L.; Wen, L., Engineered PES/SPES Nanochannel Membrane for Salinity Gradient Power Generation. Nano Energy 2019, 59, 354362.

[S10] Zhang, Z.; Kong, X.; Xiao, K.; Liu, Q.; Xie, G.; Li, P.; Ma, J.; Tian, Y.; Wen, L.; Jiang, L., Engineered Asymmetric Heterogeneous Membrane: A Concentration-gradient-driven Energy Harvesting Device. J. Am. Chem. Soc. 2015, 137, 14765-14772.

[S11] Xin, W.; Zhang, Z.; Huang, X.; Hu, Y.; Zhou, T.; Zhu, C.; Kong, X.; Jiang, L.; Wen, L., Highperformance Silk-based Hybrid Membranes Employed for Osmotic Energy Conversion. Nat. Commun., 2019, DOI:10.1038/s41467-019-11792-8.

[S12] Ji, J.; Kang, Q.; Zhou, Y.; Feng, Y.; Chen, X.; Yuan, J.; Guo, W.; Wei, Y.; Jiang, L., Osmotic Power Generation with Positively and Negatively Charged 2D Nanofluidic Membrane Pairs. Adv. Funct. Mater. 2017, 27, 1603623 .

[S13] Li, R.; Jiang, J.; Liu, Q.; Xie, Z.; Zhai, J., Hybrid Nanochannel Membrane Based on Polymer/MOF for High Performance Salinity Gradient Power Generation. Nano Energy 2018, 53, 643-649.

[S14] Xiao, T.; Zhang, Q.; Jiang, J.; Ma, J.; Liu, Q.; Lu, B.; Liu, Z.; Zhai, J., pH-resistant Nanofluidic Diode Membrane for High-performance Conversion of Salinity Gradient into Electric energy. Energy Tech. 2019, 7, 1800952 .

[S15] Xiao, K.; Giusto, P.; Wen, L.; Jiang, L.; Antonietti, M., Nanofluidic Ion Transport and Energy Conversion through Ultrathin Free-standing Polymeric Carbon Nitride Membranes. Angew. Chem. Int. Ed. 2018, 57, 10123-10126.

[S16] Yu, C.; Zhu, X.; Wang, C.; Zhou, Y.; Jia, X.; Jiang, L.; Liu, X.; , Lei Jiangb,; Wallace, G. G., A Smart Cyto-compatible Asymmetric Polypyrrole Membrane for Salinity Power Generation. Nano Energy 2018, 53, 475-482.

[S17] Sui, X.; Zhang, Z.; Li, C.; Gao, L.; Zhao, Y.; Yang, L.; Wen, L.; Jiang, L., Engineered Nanochannel Membranes with Diode-like Behavior for Energy Conversion over a Wide pH Range. ACS Appl. Mater. Interfaces 2019, 11, 23815-23821. 
[S18] Zhang, Z.; Yang, S.; Zhang, P.; Zhang, J.; Chen, G.; Feng, X., Mechanically Strong MXene/Kevlar Nanofiber Composite Membranes as High-performance Nanofluidic Osmotic Power Generators. Nat. Commun. 2019, DOI: 10.1038/s41467-019-10885-8.

[S19] Xin, W.; Xiao, H.; Kong, X.; Chen, J.; Yang, L.; Niu, B.; Qian, Y.; Teng, Y.; Jiang, L.; Wen, L., Biomimetic Nacre-like Silk-crosslinked Membranes for Osmotic Energy Harvesting. ACS Nano, 2020, 14, 9701-9710.

[S20] Zhang, Z.; Zhang, P.; Yang, S.; Zhang, T.; Zhang, T.; Löffler, M.; Shi, H.; Lohe, M. R.; Feng, X., Oxidation Promoted Osmotic Energy Conversion in Black Phosphorus Membranes. PNAS, 2020, 117, 202003898.

[S21] Chen, W.; Wang, Q.; Chen, J.; Zhang, Q.; Zhao, X.; Qian, Y.; Zhu, C.; Yang, L.; Zhao, Y.; Kong, X.; Lu, B.; Jiang, L.; Wen, L. Improved Ion Transport and High Energy Conversion through Hydrogel Membrane with 3D Interconnected. Nano Lett. 2020, 20, 5705-5713.

[S22] Chen, J.; Xin, W.; Kong, X.; Qian, Y.; Zhao, X.; Chen, W.; Sun, Y.; Wu, Y.; Jiang, L.; Wen, L. Ultrathin and Robust Silk Fibroin Membrane for High-performance Osmotic Energy Conversion. ACS Energy Lett. 2020, 5, 742-748.

[S23] Sun, Y.; Dong, T.; Lu, C.; Xin, W.; Yang, L.; Liu, P.; Qian, Y.; Zhao, Y.; Kong, X.; Wen, L.; Jiang, L. Tailoring Poly(ether sulfone) Bipolar Membrane for Osmotic Energy Generator with High Power Density. Angew. Chem. 2020, 59, 17423-17428. 